\title{
A Case Study of New Teachers' Role Identity in China
}

\author{
Xuan Dong \\ College of Education Administration \\ Beijing Normal University \\ Beijing 100875, China \\ Tel: 86-10-5880-1300Ｅ-mail: dongx@126.com
}

\begin{abstract}
In the context of social expectation and identification, it is worthy of studying the construction of new teacher's role identity. As a case study, this paper adopted the methods of observation, interview, and open-ended questionnaire to examine a new teacher's daily life in schooling context. It has been found that the new teacher's role-identity differs greatly from social expectation. It is concluded that the role awareness and role behavior of the new teacher are, to some extent, conflicted, expecially in the understanding and identification of a teacher and his own career development. This conflict should be reflected and given more emphasis in the teachers' continuing education and training.
\end{abstract}

Keywords: New teacher, Role-identity, Role awareness

\section{Introduction}

For a long period, teacher is regarded to play the roles of knowledge initiator, learning director, educational scientific researcher, strict governor, the model of students and etc. (Luo, 2004). Meanwhile, Chen investigates and analyses the teachers' role from multiform metaphorical views of engineer theory, gardener theory, barrel theory and candle theory etc(Chen,2000). But they are only the social cognitions for this career, or we can say that they are the social expectations and demands for teachers. Generally speaking, due to the effects of social norms and public opinions, quasi-teacher enters their occupational field with the amalgamation between social expectations and their own recognitions. So, this paper will be greatly concerned with two problems as follows: what kind of condition does the new teacher state in real school context? And what is the influence of the condition on teachers' career and professional development?

\section{Role Identity}

Role identity is a psychological term, which means one tends to be the same with other individuals or groups according to imitating and internalizing the behavior manner, attitudinal notion and value criteria. Self-identity is formed as a reflective self by one's own experience. It is the continuity of the actor's reflective explanation. The self is divided into the "I" and "me", which is based on the conclusions of earlier generations studied by George. Mead."I" means the organism' responses to others' attitudes, while "me" is a set of organized others' attitudes adopted by the organism himself. "I" is formed by others" attitudes organically, and then, the organism reflects it as the "me" (Mead,2005). Mead thought that we could not recognize "I" completely, thus we would still be surprised at some behavior (Turner,2004:39). If we can say that it is possible for the social reform because of the "I", the "me" will be an important assurance for the society to carry out its function.

Social identity is a common identity of a certain group. It emphasizes the similitudes among the collective members and some certain common or similar features which they believe. Some researchers indicate that we had better admit that there are some sub-identities while defining the identity (Mishler,1999). To this point, role identity is formed by the development of some sub-identities which are embedded in different social contexts. The teacher's identity is also relative to some sub-identities under the certain context. As Cooper and Olson(1996) said, the feelings to be a teacher will be influenced by historical, social, psychological and cultural factors.

In essence, new teachers' role identity is a process through re-cognizing oneself between social and self identity. In this process, several facets on the new teachers' role identity will experience some changes such as the understandings on role position and norm. Teachers' attitude and behavior, in addition, are based on how they recognize and interpret the lifestyle in school. Thus, the primary occupational role identity of new teacher is influenced by school culture, social 
expectation, power relation, and self-portraits on career development.

\section{Methods}

Social science is a terminological jungle where many labels compete, and no single label has been able to command the particular domain before us. Often, researchers simply "do it" without worrying about giving "it" a name (Lofland and Lofland,1984). Even so, every research has its own theoretical and methodological braces. Methodology can be understood as a kind of thinking to formulate and make explicit inquiry procedures and reflect on instruments obtained in practice (Weber,1968). According to the basic rules on qualitative research, this case study chose a math teacher who had experienced his career life only 6 months since the research started. In order to gather effective data, this research employed the methods of observation, interview and open-ended questionnaire to examine a new teacher's daily life in schooling context. In this paper, the math teacher is refered to $\mathrm{Hu}$ as a pseudonym, according to his own wish.

\section{Data Collection}

For teachers, school is an important field to carry out their occupational roles. In other words, the interplay between peer group and teacher-student interaction shape or reshape the original role consciousness. As a math teacher, Hu teaches in a senior school which comprises 50 teaching classes including about 4200 students and 162 teachers now.

\subsection{To be a skilled worker}

$\mathrm{Hu}$ teaches in Class 1 and Class 2 in first grade, which contain 127 students in total. The average marks in math are 67 for class 1 and 61.5 for class 2 in the mid-term examination. It lies in a medium level among the 18 classes of first grade in this school. The following excerpt shows a snapshot on $\mathrm{Hu}$ and his students:

Having a butch haircut, Hu was medium height, a little thin, and speaking in a moderate tone. Hu told me that the first class would begin at 7:40 a.m. When we already sat down in the classroom and the bell was screaming to tell us "It's time for class", some students still strolled outside the classroom or went towards their seats very slowly without knocking the door or explaining the reasons to $\mathrm{Hu}$. $\mathrm{Hu}$ started his lesson without saying anything else.

It was a new lesson about the formulas of trigonometric function. At 8:10 a.m., nine students became sleepy and embedded their heads into a heap of books on the desk. Hu walked around the room to remind these students not to be asleep again and to catch up with others. But it seemed to be ineffective. The students were still enjoying their sweet nap. Then $\mathrm{Hu}$ didn't supervise and accelerate again. When the bell of finishing ringed at 8:20 a.m., more than 20 students were already at roost. It seemed that they didn't care about what the homework the teacher had arranged.

After returning the office, I asked $\mathrm{Hu}$ about the problem that the students were sleeping in class, He said out his views:

"It's not easy to know what the current students think. I have thought that it would be OK if one could teach well and have a high capacity to be a teacher when I was at college. But it seems not to be the same as what I think. The students do not listen to me. It's also useless even though one teaches well. Now I feel that teachers, to some extent, are workers in the streamline and it's all right to achieve the acceptance rate, because high marks in exams are everything we should focus on. So we do not need to make all of the students be up to standard, what we should or must do is ignoring some of the students to guarantee others' academic achievement"

According to his own words, it is easy to find that Hu's cognition about teachers' occupation differs greatly from the social expectations. In his opinion, teachers are just skilled workers who focus on checking. Hu's strong task orientation proved his opinion.

\subsection{To be a babysitter or not}

$\mathrm{Hu}$ often refers two statements, one is "I'm a babysitter, not a teacher," the other is "I'm wanna be a friend with the students, but is that true?" Hu has tried to be a nice teacher, but the reality is not as simple as his expectation. He told his confusion below:

9:10 a.m., the finishing bell was ringing on time. Hu spoke a little quicker. Without saying that the class is over, the students had been in a lazy state. Some whispered to others, some laughed loudly, and some already stood up, ready to go outside the room. Hu did not say anything else, even forgot to say "guys, class is over." He went to a boy's seat in the sixth row, asking him to hand in his handheld game console. The boy showed his cunning smile and said, "what's the game machine? I've no idea what are you saying about, sir." Hu commanded sternly, but the boy was not afraid of him and suddenly passed the game machine to another student. Then the game machine had been passed one by one among the students, they screamed, laughed, like having a party. Hu was boiling and losing his head a bit. Then, a boy caught the chance to tease, "Mr. Hu, aren't you down with him?" Hu turned to the right aisle from the left in the classroom and said in a low voice while passing me, "I still can punish you, you son of bitch." After a round of chasing, $\mathrm{Hu}$ finally caught the student and his game machine.

It indicates that the students are not identified $\mathrm{Hu}$ as a teacher. In another word, $\mathrm{Hu}$ does not have the necessary authority in order to keep students not crossing the line. Here is the reason for this in the follow interview: 
"I think it would be good for teaching if I can got along well with the students at the beginning of working. At that time, I was really wanna be a friend with the students, but was that true? I have found that if a teacher treats the students as friends, they will not regard him as a teacher in class, and then, the order of class also will be disturbed."

So how do the students treat this? A survey has been made for the two classes taught by Hu, including 127 students with open-ended questionnaires. There are two open-ended questions examined:

1. In your opinion, what are the differences between the veteran and novice teacher, and what kind of teachers do you prefer to ask questions, why?

2. If you were a middle school teacher, just graduating from college, how would you deal with the relation with the students, and how would you be approbated by them?

In the 108 effective questionnaires reclaimed, four key words have been highlighted in students' description about the novice teacher, which are "lacking experience", "energetic", "approachable" and "unobtrusive" respectively. For the second question, the method of "making friends with students" is mentioned directly or indirectly in the 92 questionnaires.(See Table 1)

These key words are "native concepts" which means "people use these concepts to interact with each other in their particular social context" (Chen,2000). Thus, to understand these concepts should go back to the students who use them. That is to say, to know what these concepts means needs to interview the students who ever grasp these words. Based on this point, a group interview has been made in Hu's two classes. The interview employed the way of team-discussion. There are 15 to 20 students in a team which had a spokesman, and others could only tell him their opinions and then the spokesman would speak them out to the interviewer. From the group interview, native understandings about the four native concepts are detailed in Table 2.

About $\mathrm{Hu}$, students in the two classes hold a very similar view below:

"In the beginning, he was nice and usually chatted or played football with us, but later he was stern to us and there were no jokes in class or out. There is nothing else except teaching now. As a matter of face, it was very boring."

\subsection{Too close to official hour}

For new teachers, colleagues who effect greatly for their professional development are the important others in the process of shaping their role identity. To communicate with colleagues and to learn from school culture or sub-culture is beneficial to establish one's identity on career. In addition, learning from veteran teachers as an apprentice is in fashion in many Chinese schools. It is all there for a reason that novice teachers can learn the basic rules to survive in daily schooling life. But Hu flatly complained this mechanism in strong terms stating that veteran colleagues had given him nothing but trouble and that he viewed them as competitors.

“Now, the results of students' exams are like traffic lights which lead teachers' career development. When students did not get the approving grade, the zebra lines were not available for the teacher who was responsible for their academic achievement. This is the root of problems. We are alone here, no one wants to care about others. At the very beginning when I came to this school to teach math, I did not know these sub-rules very well. About a month later, the first grade had a usual test for students. The teachers marked the test papers of others' class. Well, maybe I was a bit severe, the marks of the papers which I took charge are lower than the average. Consequently, the scores of my class were very low in the next test because of revenge. It sounds ridiculous, right? But it is true, it is the damn sub-rules in school. I cannot change it, so I have to follow it."

The senior middle school where $\mathrm{Hu}$ earns his living, ranks the third place among 8 senior middle schools in N.A., a small town in Jilin province in China. Its notion of school management updates more frequently than others, especially in how to improve teachers' professional abilities. Thus, it encourages people to establish support groups for cooperative learning, such as sharing advanced teaching skills, discussing psychological problems, and forcing identities in the learning community. During the process of professionalization, the teachers have to attend a meeting monthly according to the ideas mentioned above. Here is a snapshot for one of the meetings:

Time: 4:10 p.m.

Site: Room 305 in the main building

Members: First-grade math teachers

Meeting process: The leader of the teaching group presided and spoke firstly. There were two points in main content. Firstly, to sum up the quantity of the task that each teacher had accomplished for the students' homework, mainly about exercise papers for last month. Secondly, to arrange new teaching tasks. Then the leader asked whether there were any questions or not. No one responded. During the whole meeting, the leader was like a lonely dancer without any partners, even no spectators.

It seems that the meeting is one bane of teachers' life in school. The administrators urge teachers to take the meeting as 
a chance to improve themselves, but this does not lessen their very real, often poignant experience of the "official affairs". Hu provides his opinions on this:

"It is really important to fix some problems together, that we have encountered commonly in school. But everyone is busy on his or her own business. And you know, no one likes attending a meeting, no one can put up with it. It is so boring."

\section{Discussion and Conclusion}

Upon experiencing paradoxes in school life and reflecting on the interplay through others, it seems clear to Hu that his emotions - his hopes, fears, and passions - had at least as heavy a role to play as did his cognitive grasp of the work in how he came to, planned for, and carried out. This is not only his confusion, but also an important topic discussed in different academic fields. $\mathrm{Wu}(2002)$ points out that teachers have the right to choose their own lifestyle and view on this career. In Wu's opinion, teachers are not just "spokesmen", but also "public intelligentsia". It becomes a tendency to define the teachers' role more pragmatically on account of focusing on a teacher as a person and listening to the teachers' group. Zhou (2006) further claims that teacher is not only a role person in teaching but also a nature person.

As a novice teacher, students and colleagues are the most important others through Hu's experience in school context. As a very important view from symbolic interactionism school in Sociology, it argues that individuals often construct their identities through the interactive process and context which needs the important others to be the reference to integrate the "I" and "me". It claims that not only can the contexts construct individuals' role identity but also individuals' identity through its action can reconstruct the contexts. That is to say, role identity is not just the product of contexts, but it also produces contexts of its own. In summary, role identity is constructed in the interaction between individuals and important others. It can change with the changes of contexts in which individuals and others exist. Among these changes, one of the most important factors is the cultural characteristics and experiences that individuals and other colleagues or students hold in school. Another critical point is how individuals and others perceive themselves and how they respond to others' perception of them in interaction processes on the basis of their respective school experience.

Based on the data being collected, Hu did not achieve the essential identity from the interaction with important others. On contrary, the evaluation system pushes $\mathrm{Hu}$ to expose under the great pressure that he must be responsible for students' achievement. It also makes some delicate changes between students and him. In terms of the confusion Hu faces, how to form an appropriate identity for new teachers becomes a very serous problem.

Briefly speaking, we have to reflect the current normal education in China. Zhu (2005) points out that the education and training in normal colleges only focus on professional skills and knowledge without paying essential attention to cultural visions. It will put normal education into a critical dangerous situation because of the tool rationality which makes individuals devote their attention to how to do things well, not why to do or where to go.

In conclusion, how to form a scientific role consciousness for teachers especially the new teachers, how to find a suitable point of equilibrium between social expectation and individual identity for new teachers, and how to guide new teachers in school context ideologically or culturally are critical problems. They need to be taken into account seriously and to be resolved promptly.

\section{References}

Chen, X. M. (2000). Qualitative Research Method and Social Science research. Beijing:Educational science press.

Chen, X. M. (2001). What are Teacher's Functions: An Analysis of Some Teacher Metaphors in the Chinese Language. Educational Research and Experiment. 1:13-19.

Cooper, K. \& Olson, M. R. (1996). The Multiple "I"s of Teacher Identity, In M.Kompf, Bond,W.R., Dworet,D., Boak,R.T. Changing Research and Practice:Teachers' Professionalism, Identities and Knowledge. London/Washington, DC:The Falmer Press.

Giddens, A. (2003). Sociology (4 $4^{\text {th }}$ ed). Beijing: Peking University Press.

Goodson, I. F. \& Cole, A. L. (1994). Exploring the Teacher's Professional Knowledge: Constructing Identity and Community. Teacher Education Quarterly, 21(1).

Lian, J. (2005). Social Transformation and Intellectuals' Role-identification. Nankai Journal(Philosophy, literature and social science edition).6:57-61.

Lofland, J. \& Lofland, L. H. (1984). Analyzing Social Settings: A Guide to Qualitative Observation and Analysis. Belmont, CA: Wadsworth.

Luo, F. R. (2004). Primary construction of teachers' role need theory. Contemporary Education Science. 13:3-6.

Mead, G. H. (2005). Mind, Self and Society. Shanghai:Shanghai Foreign Language Press. 
Mishler, E. G. (1999). Storylines: Craft Artists'Narratives of Identity. Cambridge, MA: Harvard University Press.

Ritzer, G. (2004). Contemporary Sociological Theory and Its Classical Roots:The Basics. Beijing: Peking University Press.

Turner, J. H. (2004). The Structure of Sociological Theory( $7^{\text {th }}$ ed). Beijing:Peking university press.

Wang, R. Z. (2006). The obstacles and countermeasures on new teachers' role socialization. Modern Education Science. 5:11-12.

Weber, M. (1968). The Methodology of the Social Sciences(Translated by Shils,E.A. and Finch, H.A.). New York: Free Press.

Wu, K. N. (2002). Are Teachers “Social Spokemen”?. Educational Research and Experiment,2:23-29.

Zhang, X. D. (2006). The concepts of Identity. Hunan Social Science. 3:78-80.

Zhou, X. J. (2006). Teachers: Stepped between role persons and nature persons. Educational Research and Experiment. $3: 41-45$.

Zhu, Z. Y. (2005). A Case Study of Ethnic Schoolteachers' Role Awareness. Tsinghua Journal of education. Vol.26, 6: 90-98.

\section{Notes}

Note 1: The number of the students who refer to the relative key words is noted in the brackets.

Table 1. The results of the survey (See Note 1)

\begin{tabular}{|l|l|l|l|l|}
\hline \multicolumn{2}{|c|}{ Questions } & \multicolumn{4}{|c|}{ Key words mentioned in questionnaires } \\
\hline $\begin{array}{l}\text { Differences between } \\
\text { veteran and novice }\end{array}$ & Lacking experience(87) & $\begin{array}{l}\text { Energetic } \\
(81)\end{array}$ & $\begin{array}{l}\text { Approachable } \\
(74)\end{array}$ & $\begin{array}{l}\text { Unobtrusive } \\
(66)\end{array}$ \\
\hline $\begin{array}{l}\text { How to get along with } \\
\text { students }\end{array}$ & $\begin{array}{l}\text { Making friends with } \\
\text { students(92) }\end{array}$ & $\begin{array}{l}\text { No } \\
\text { sternness(86) }\end{array}$ & $\begin{array}{l}\text { Talking } \\
\text { privately (74) }\end{array}$ & $\begin{array}{l}\text { Skilled } \\
\text { humorous } \\
\text { teaching(45) }\end{array}$ \\
\hline
\end{tabular}

Table 2. Understandings of native concepts

\begin{tabular}{|l|l|}
\hline Local Concepts & \multicolumn{1}{|c|}{ Comprehension } \\
\hline $\begin{array}{l}\text { Lacking } \\
\text { experience }\end{array}$ & $\begin{array}{l}\text { be dogmatic on textbook; teach little about skills of passing exams; have no idea what students } \\
\text { think about. }\end{array}$ \\
\hline Energetic & Young; joke with students; play football together. \\
\hline Approachable & communicate with students after class; not be stern. \\
\hline Unobtrusive & discuss with students; correct the his own mistakes without being angry. \\
\hline
\end{tabular}

